\title{
REGIONAL DEMAND FOR NATURAL GAS IN THE RESIDENTIAL SECTOR
}

\author{
Stephen T. Grady*
}

\section{Introduction}

Natural gas, a clean and efficient primary energy source for consumers, currently accounts for about 30 percent of the net energy consumption in the U.S. and 50 percent of the net energy consumption in the combined residential and commercial sectors. However, current regional gas consumption patterns reflect the past market conditions under which natural gas was traded-regulated markets with price oftimes below market clearing levels.

The Natural Gas Policy Act of 1978 provides for partial price deregulation by 1985 . Also, the U.S. Congress is considering complete deregulation, possibly on an accelerated time schedule. The movement to a partial or no price regulation position entails changes in consumer consumption patterns of natural gas and natural gas appliances as well as other energy sources as prices are allowed to move toward market-clearing levels. To understand potential consumer responses to these changes, estimates of natural gas demand parameters are required.

The purpose of the research documented in this article is to consider functional form specification with non-spherical disturbances on residential natural gas demand parameters estimated for five availability regions in the United States with state data for the years 1968-1978. The data used in the analysis indicate two suspected sources of heteroscedasticity, unequal sample size and other unobservable cross-sectional effects. Several studies have been undertaken to examine the effects of functional form specification bias using the transformation-of-variables technique introduced by Box and Cox [9]. ${ }^{1}$ In general, the

\footnotetext{
*Economist, Science Applications, Inc., Oak Ridge. The author wishes to thank H. Chang, H. Herzog, S. Martin, and an unknown referee for helpful comments on an earlier version of this paper. Any remaining omissions or errors are the responsibility of the author.
}

application of this technique has used the assumption that, after any transformations, $\epsilon \sim$ IN $\left(0, \sigma^{2} \mathrm{I}\right)$, where $\epsilon$ is a random error term with an independent, normal distribution, $\sigma^{2}$ is the constant variance of $\epsilon, I$ is an $(n \times n)$ identity matrix, and $\mathbf{n}$ is the number of observations. In this article, a technique is demonstrated for analyzing pooled cross section and time series data with the assumption that, after any transformations, $\epsilon \sim N(0, \Omega)$, where $\Omega$ is the variancecovariance matrix of $\epsilon$. Previous estimations of a residential natural gas demand function have been undertaken with linear or linear-in-logs specifications, thereby ignoring the question of functional form specification bias. ${ }^{2}$

The next section of this paper presents the general specification of the residential natural gas demand function used for each of the five availability regions. The estimation technique is presented in the third section, with the results of estimation in the fourth section. In the final section, the empirical results are used to analyze the current situation (1983) in the natural gas market.

\section{Residential Natural Gas Demand}

The consuming unit to consider for natural gas demand is the individual gas household. Within a household, natural gas is typically utilized for space heating, water heating, clothes drying, or cooking, suggesting that household consumption of natural gas will be a function of relative prices of natural gas and possibly other energy sources, weather conditions, and household income.

The dependent variable is the ratio of total gas consumed in the residential sector to the total number of residential gas customers, both for state $j$ at time $t^{3}$ Specification of ownprice and income requires that a price index defined on the same basis as nominal prices and income be available. Since a price index for states from 1968-1978 was not available, an index was estimated using the expenditures required for a household of four to maintain an intermediate standard of living published by 
the Bureau of Labor Statistics. The complete development of this index is considered elsewhere [15]. Other prices are fuel oil and electricity. The expected signs for own-price and income effects are negative and positive, respectively. The expected signs for the prices of fuel oil and electricity are not easily determined a priori due to the nature of residential energy use. This point is considered in more detail in the fourth section. Heating degree days were included in the analysis to account for variations in winter weather. Since the primary use of natural gas in households is for space heating, this variable should have a positive impact on determining the quantities of natural gas consumed.

Another factor influencing natural gas demand and not usually considered in the traditional demand specification discussed above is the past availability of gas. ${ }^{4}$ Due to the structural characteristics of the U.S. natural gas market, there is probably substantial regional variation in the household appliance stock mix, appliance efficiency, and flexibility in switch- ing energy sources. Availability of natural gas in any region is determined by two primary factors-marketed production and existing gas pipelines. Neither of these factors change dramatically over short time periods but they do vary substantially over space, suggesting that the inclusion of variables in the estimating specification to account for past availability may not yield satisfactory results. To circumvent this problem, and the fact that no one variable can adequately express availability, another approach was used which allowed the sample to be segregated into state groups according to availability characteristics. ${ }^{5}$

Table 1 summarizes the state groupings. Five distinct availability regions resulted. The procedure used to group the states into availability regions classified 43 of 51 (84 percent) states. Eight states did not obviously belong to a particular group and were grouped according to similarity of response. ${ }^{6}$ In terms of availability characteristics, group 1 states were about average in both the amount of gas pipelines and the volume of marketed produc-

Table 1

State Groups According to Availability Characteristics

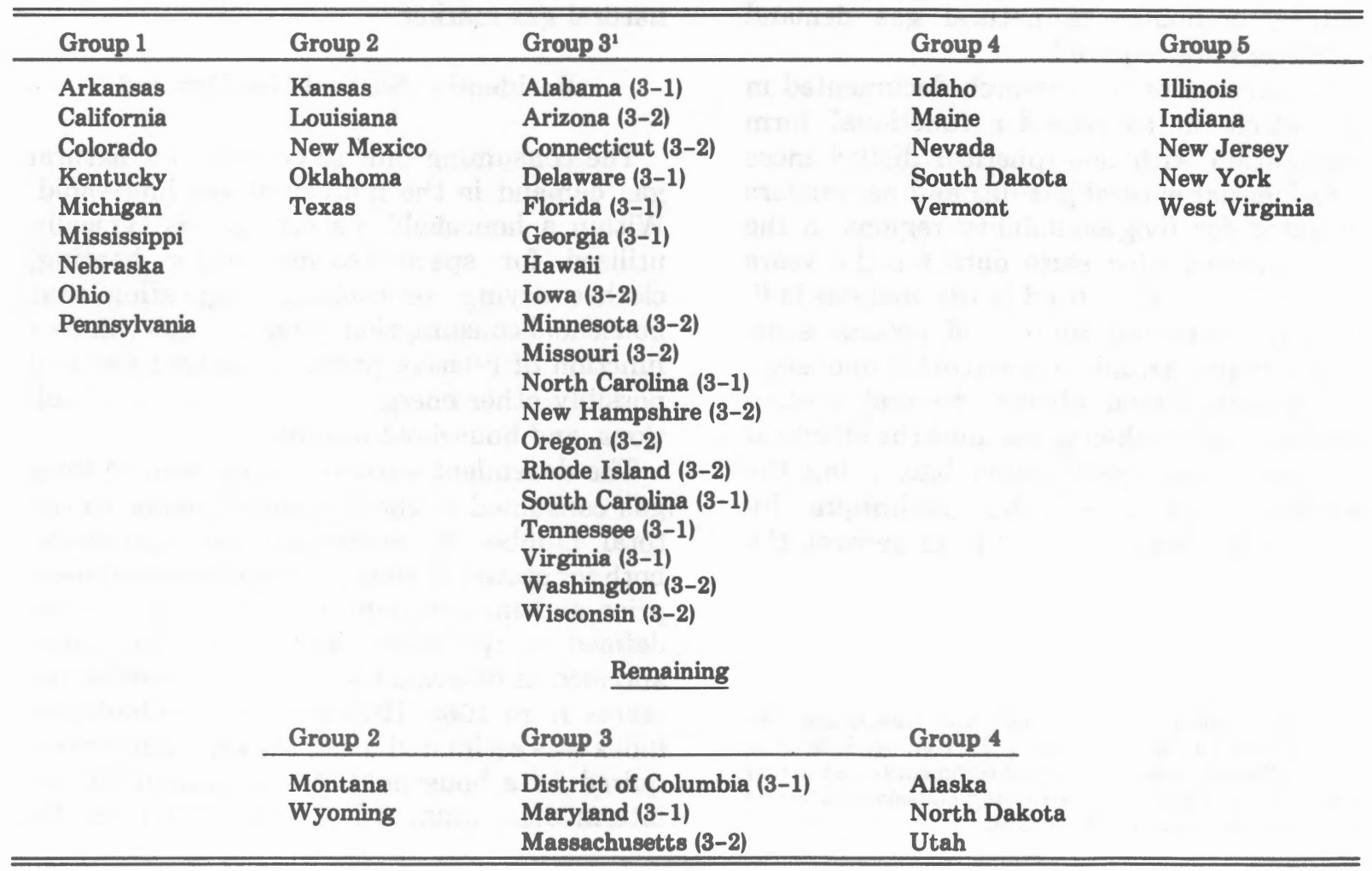

${ }^{1}$ Numbers in parentheses indicate subgroup used for analysis. 
tion. Several of these states had substantial production of natural gas, notably California, but little or none of the gas was exported outside the state. On the other hand, group 2 states were major natural producers with welldeveloped pipeline systems. Group 3 states were characterized by a well-developed natural gas pipeline system but low or zero levels of marketed production. Group 4 states had low amounts of pipelines and virtually no marketed production. Group 5 states had both a large amount of natural gas pipelines per square mile and per household and a low volume of marketed production. The states in this final group were heavily dependent on the interstate pipeline system to supply natural gas to large residential markets.

The final variable included in the analysis is a proxy for information available to a typical household. The argument is that, ceteris paribus, a typical household will consume more natural gas, on average, as the information available on gas utilization increases. This response is related to the publicity surrounding natural gas explosions or other mishaps caused by faulty gas home heating systems. Since these system failures are highly unlikely events, it seems reasonable to assume that any reticence of a household to use gas appliances would be overcome by observation of successful use of natural gas by many neighbors. To account for this factor, the ratio of gas households to total households is included as a proxy variable and is expected to have a positive effect on gas consumption.

In summary, for each of the availability regions the average consumption of natural gas per gas household in state $j$ at time $t$ was specified as a function of own-price, real income, fuel oil and electricity prices, heating degree days, and the ratio of gas households to total households. ${ }^{7}$ All prices and income were defined by weighting the nominal values by the reciprocal of the state price index. To account for the fact that the existing gas appliance stock within a typical gas household may restrict the ability of the household to respond to changes in the relative price of natural gas or other factors, the partial adjustment framework was used to develop the final specification [19, p. 476-477]. This resulted in an additional independent variable which was the value of the dependent variable lagged one period. ${ }^{8}$ The estimation technique is considered in the next section.

\section{Estimation Technique}

The previous development of the demand equation was not predicated upon an assumed functional form. To investigate the importance of the functional form, the following general equation was used:

$$
Y^{(\lambda)}=X^{(\lambda)} \beta_{1}+Y_{-1}^{(\lambda)} \beta_{2}+\epsilon
$$

where $Y^{(\lambda)}$ is a $(N T \times 1)$ vector for the dependent variable, $X^{(\lambda)}$ is a (NTxk) matrix of $\mathbf{k}$ independent variables, $\beta_{1}$ is a $(\mathbf{k x l})$ vector, $Y\left({ }_{-1}\right)$ is a (NTxl) vector for the lagged dependent variable, $\beta_{2}$ is a scaler, the error vector, $\epsilon_{1}$ is (NTx1), $\mathrm{N}$ is the number of cross-sectional observations, and $T$ is the number of time periods. $Y^{(\lambda)}, X^{(\lambda)}$, and $Y_{-1}^{(\lambda)}$ are observations on $Y, X$, and $Y_{-1}$, respectively, that have been transformed according to the transformation function $(\lambda)$. This assumption implies that additivity of the main effects holds on some transformed scale for $\mathrm{Y}$ and $\mathrm{X}$.

Box and Cox suggest estimating the parameters of equation (1) by forming the likelihood function of $Y$, assuming that the error term of equation (1) is normally and independently distributed with zero mean and constant variance and using the general transformation $Y^{(\lambda)}=\left(Y^{\lambda}-1\right) / \lambda$.

Although Box and Cox assumed $\epsilon \sim \operatorname{IN}\left(0, \sigma^{2}\right.$ I) after a transformation, Zarembka has shown that if the homoscedasticity assumption is not met in the transformed scale the estimates of both $\lambda$ and $\beta$ will be biased and inconsistent [25]. Since the data in this study are group averages defined over states, the existence of heteroscedasticity caused by the variation in market size across states can be shown." Therefore, after any transformation, the variables are weighted by the square root of the number of residential gas customers and the weight is a separate independent variable, where the estimate of the intercept is the coefficient of the weight variable.

Using this weighting procedure, estimation is undertaken without an intercept. Schlesselman [22] has shown that the transformation suggested by Box and Cox is not invariant to the units of measurement for the dependent variable if an intercept is not included. Therefore, the transformation used is 


$$
Y^{(\lambda)}=Y^{\lambda} / \lambda \text {. }
$$

Although the transformation of equation (2) is not continuous at zero, the Jacobians of both the Box and Cox transformation and the equation (2) transformation are equivalent.

Therefore, the transformation of equation (2) is motivated by the heteroscedasticity correction for unequal sample size used in this analysis. Although the results of this heteroscedasticity correction are equivalent to a generalized least squares (GLS) approach with a consistent estimate of the variancecovariance matrix, its use to account for the effects of heteroscedasticity is based upon consistent first-round estimates of the model parameters so that the elements of the variance-covariance matrix can be estimated, a condition that does not hold, as shown by Zarembka, when the functional form is generalized under conditions of heteroscedasticity. The following discussion develops a technique that can be used to estimate the demand functions, with the heteroscedasticity correction applied, as required, after variables are transformed using equation (2).

The assumption of Box and Cox of normally distributed and independent error terms is relaxed by using the assumption that the error terms, after the transformation $(\lambda)$, have a joint normal distribution but are not necessarily independent. This can be stated as:

$$
\epsilon \sim \mathbf{N}(\mathbf{O}, \Omega)
$$

with the resulting log likelihood function

$$
\begin{aligned}
\mathrm{L}_{\max }= & -(\mathrm{n} / 2) \log 2 \pi-(1 / 2) \log |\Omega|- \\
& (1 / 2) \epsilon^{\prime} \Omega-^{-1} \epsilon+(\lambda-1) \Sigma \log \\
& \mathrm{Y}_{\mathrm{jt}}(3)
\end{aligned}
$$

where $\Omega=\epsilon \epsilon^{\prime}$ and is a (NTxNT) variancecovariance matrix; the last term is the log of the Jacobian of the transformation of equation (2); and all other variables are defined in equation (1). Since the inclusion of the lagged dependent variable does not, per se, cause any estimation problems under the partial adjustment framework, it is included in the $\mathrm{X}$ matrix [16, p. 82]. Substituting for $\epsilon$ into (3) and solving for $\beta$, for a fixed $\lambda_{1}$ by setting the derivative of $L_{\max }$ with respect to $\beta$ equal to zero results in

$$
\left.\beta^{*}=\left(X^{(\lambda)} \Omega^{-1} X^{(\lambda)}\right)^{-1}\left(X^{(\lambda)}\right) \Omega^{-1} Y^{(\lambda)}\right)
$$

which is equivalent to the Aitken generalized least squares estimate of $\beta[19$, p. 505,506$]$.
Since $\Omega$ is not known, an estimate has to be used in equation (4). Zellner has shown that if a consistent estimate of $\Omega$ is utilized, the asymtotic properties of the estimator are the same as those of the estimates in equation (4) [26]. Therefore, for a given $\lambda$ and a consistent estimate of $\Omega$, say $\Omega^{*}$, the likelihood function can be estimated by

$$
\begin{aligned}
\mathrm{L}_{\max }(\lambda)= & -(n / 2) \log 2 \pi-(1 / 2) \log \left|\Omega^{*}\right| \\
& -(1 / 2)\left(Y^{(\lambda)}-X^{(\lambda)} \beta^{* *}\right)^{\prime} \Omega^{*-1}\left(Y^{(\lambda)}\right. \\
& \left.-X^{(\lambda)} \beta^{* *}\right)+(\lambda-1) \Sigma \log Y_{j t}(5)
\end{aligned}
$$

where $\beta^{* *}$ results from equation (4) with $\Omega^{*}$ substituted for $\Omega$.

A consistent estimate of $\Omega$ can be found by utilizing the method of Wallace and Hussain [24] for pooling cross section and time series data. Following these authors, the assumption is made that the error term of equation (1), $\epsilon$, has three components, $v_{j}, e_{t}$, and $u_{j t}$ which reflect cross section, time, and random effects, respectively, and

$$
\epsilon_{j t}=v_{j}+e_{t}+u_{j t}
$$

where

$$
\begin{aligned}
& v_{j} \sim N\left(0, \sigma_{v}^{2}\right) ; e_{t} \sim N\left(0, \sigma_{e}^{2}\right) ; u_{j t} \sim N\left(0, \sigma_{u}^{2}\right) \\
& E\left(v_{j} e_{t}\right)=E\left(v_{j} u_{j t}\right)=E\left(e_{t} u_{j t}\right)=0 \\
& E\left(v_{j} v_{l}\right)=0 \text { for } j \neq 1 \\
& E\left(e_{t} e_{s}\right)=0 \text { for } t \neq s \\
& E\left(u_{j t} u_{j s}\right)= E\left(u_{j t} u_{l t}=E\left(u_{j t} u_{l s}\right)=0\right. \text { for } \\
& j \neq 1 \text { and } s \neq t .
\end{aligned}
$$

Together these assumptions imply the necessary homoscedastic error term.

Use of the error component model allows the incorporation of random time and cross-sectional effects that are not included explicitly in the analysis. Estimates of their respective variances are used to provide more efficient parameter estimates. Due to the institutional and regulatory constraints of the residential natural gas market, the impacts of left-out cross-sectional and time factors are not likely to have a transitory impact on natural gas demand indicating that the error components model is well-suited to this research. 
The variance-covariance matrix is of the following form,

$$
\Omega=\left[\begin{array}{llll}
A_{11} & A_{12} & \ldots & A_{1 N} \\
A^{21} & & & \\
\vdots & & & \\
A_{N 1} & \ldots & A_{N N}
\end{array}\right]
$$

where each matrix $A$ is ( $T \times T$ ) and of the following general form:

$$
\begin{aligned}
& A_{\mathrm{nm}} \text { where } \mathrm{n}=\mathrm{m}: \\
& \text { diagonal elements }=\sigma_{\mathrm{u}}^{2}+\sigma_{\mathrm{v}}^{2}+\sigma_{\mathrm{e}}^{2}=\sigma^{2}, \\
& \text { off-diagonal elements }=\sigma_{\mathrm{v}}^{2}, \\
& \mathrm{~A}_{\mathrm{nm}} \text { where } \mathrm{n} \neq \mathrm{m}: \\
& \text { diagonal elements }=\sigma_{\mathrm{e}^{\prime}}^{2} \\
& \text { off-diagonal elements }=0 .
\end{aligned}
$$

Although $\Omega$ is an NTxNT matrix, there are only four different elements $-\sigma^{2}, \sigma_{\mathrm{v}}^{2}, \sigma_{\mathrm{e}}^{2}$, and 0 . Wallace and Hussain have shown that under the assumptions of their model, estimates of these elements can be obtained from the ordinary least squares residuals resulting from equation (1) when the ordinary least squares estimate of $\beta$, says $\beta^{*}$, is substituted for $\beta$.

The procedure of Wallace and Hussain yields consistent estimates of the elements of $\Omega$ on the assumption that the ordinary least squares estimate of $\beta$ is consistent. Normally, heteroscedasticity does not affect the consistency of an estimator, but, when the functional form is generalized, a heteroscedastic error term biases the estimates of $\lambda$ and $\beta$. Therefore, the model subject to analysis with the Wallace and Hussain technique must have a homoscedastic error term. The weighting correction (square root of total gas customers) applied to equation (1) yields just such a model. ${ }^{10}$

The procedure for estimating $\lambda$ and $\beta$ from equation (1) is to transform the dependent and independent variables with an estimated value of $\lambda$ according to equation (2); weight the transformed observations; apply ordinary least squares to the pooled, transformed data set; use the technique of Wallace and Hussain to estimate the elements of $\Omega$ from the ordinary least squares residuals; apply generalized least squares to the pooled, transformed data by using equation (4) with $\Omega$ * substituted for $\Omega$; and estimate the likelihood function by using equa- tion (5). This procedure is repeated for appropriate values of $\lambda$ and the estimates of the likelihood function, $L_{\max }(\lambda)$, are compared. The estimate of $\lambda$ is determined by the maximum value of $L_{\max }(\lambda){ }^{11}$

The equation estimated for each availability region was of the following form:

$$
\begin{aligned}
& A_{j t}\left(Q_{j t}^{\lambda} / \lambda\right)=\beta_{0} \gamma A_{j t}+\gamma \Sigma_{k=1} \beta_{k} \\
& {\left[A_{j t}\left\{\left(P_{j t}^{k} / P_{j t}\right)^{\lambda / \lambda}\right\}\right]+\gamma \beta_{4}\left[A_{j t}\left\{\left(I_{j t} / P_{j t}\right)^{\lambda / \lambda}\right\}\right]} \\
& +\gamma \beta_{5}\left[\mathbf{A}_{j t}\left(H_{j t} / \lambda\right)\right]+\gamma \beta_{6}\left[\mathbf{A}_{j t}\left(\mathbf{T}_{j \mathrm{t}} / \lambda\right)\right] \\
& +(1-\gamma)\left[A_{j t}\left(Q_{j t-1} \lambda\right)\right]+\epsilon_{j t}
\end{aligned}
$$

where

$\mathrm{j}=1, \ldots, \mathrm{N}-$ number of states,

$t=1, \ldots, T-$ number of years,

$Q_{j t}=$ average household consumption,

$A_{j t}=$ square root of the number of gas customers,

$\mathbf{P}^{1}{ }_{\mathrm{jt}}, \mathbf{P}^{\mathbf{2}}{ }_{\mathrm{jt}}, \mathbf{P}^{\mathbf{s}}{ }_{\mathrm{jt}}=$ price of natural gas,

electricity, and fuel oil, respectively,

per 1000 BTUs,

$P_{j t}=$ index of the general price level,

$I_{j t}=$ average household money income,

$\mathbf{H}_{\mathrm{jt}}=$ heating degree days,

$\mathbf{T}_{\mathrm{jt}}=$ ratio of gas customers to total households,

$\gamma=$ adjustment coefficient, and $\epsilon_{\mathrm{jt}} \sim \operatorname{IN}(0, \Omega)$.

\section{Empirical Results}

The results of estimation are shown in Table 2. These results indicate that the consumption of natural gas by gas households responds to own-price and weather. Neither alternate energy price is significant for more than one availability region, and the signs of the coefficients are not consistently positive or negative. This result is to be expected since these prices reflect a potential substitution effect, an energy conservation effect, and a complementary goods effect. Substitution would occur when gas households substitute between appliances that perform the same function but use alternate energy sources in response to changes in relative prices. However, since most functions performed by appliances within a household are appliance-specific, the household short-run response to changes in the relative price of natural gas is usually limited to changes in the utilization rate of gas ap- 
Table 2

Results of Estimation, By State Group ${ }^{1}$

\begin{tabular}{|c|c|c|c|c|c|c|}
\hline Variable & Group 1 & Group 2 & Group 3-1 & Group 3-2 & Group 4 & Group 5 \\
\hline $\mathbf{A}_{\mathrm{jt}}$ & $\begin{array}{c}-0.0922 \\
(0.37)\end{array}$ & $\begin{array}{c}-2.43 \\
(0.64)^{*}\end{array}$ & $\begin{array}{c}0.729 \\
(0.634)\end{array}$ & $\begin{array}{l}-1.70 \\
(0.661)^{*}\end{array}$ & $\begin{array}{l}1.63 \\
(0.827)^{*}\end{array}$ & $\begin{array}{r}-0.615 \\
(0.323)\end{array}$ \\
\hline$A_{j t}\left[\left(P^{1}{ }_{j t} / P_{j t}\right)^{\lambda / \lambda}\right]$ & $\begin{array}{c}-0.00125 \\
(0.00111)\end{array}$ & $\begin{array}{l}-0.0159 \\
(0.00605)^{*}\end{array}$ & $\begin{array}{l}-1.01 \\
(0.0556)^{*}\end{array}$ & $\begin{array}{l}-0.0436 \\
(0.0153)^{*}\end{array}$ & $\begin{array}{l}-0.455 \\
(0.163)^{*}\end{array}$ & $\begin{array}{l}-0.57 \\
(0.968)\end{array}$ \\
\hline$A_{j t}\left[\left(P^{2}{ }_{j t} / P_{j t}\right)^{\lambda / \lambda}\right]$ & $\begin{array}{c}-0.00191 \\
(0.00369)\end{array}$ & $\begin{array}{c}0.00405 \\
(0.00943)\end{array}$ & $\begin{array}{c}0.245 \\
(0.361)\end{array}$ & $\begin{array}{c}0.00219 \\
(0.00958)\end{array}$ & $\begin{array}{l}0.154 \\
(0.0698)^{*}\end{array}$ & $\begin{array}{r}-0.266 \\
(0.425)\end{array}$ \\
\hline $\mathbf{A}_{\mathrm{jt}}\left[\left(\mathbf{P}^{\mathbf{s}}{ }_{\mathrm{jt}} / \mathbf{P}_{\mathrm{jt}}\right)^{\lambda / \lambda}\right]$ & $\begin{array}{c}-0.0008 \\
(0.0008)\end{array}$ & $\begin{array}{l}-0.0116 \\
(0.00382 *)\end{array}$ & $\begin{array}{c}0.36 \\
(0.29)\end{array}$ & $\begin{array}{c}0.00528 \\
(0.00898)\end{array}$ & $\begin{array}{c}0.0396 \\
(0.146)\end{array}$ & $\begin{array}{c}0.222 \\
(0.644)\end{array}$ \\
\hline $\mathbf{A}_{\mathrm{jt}}\left[\left(\mathbf{I}_{\mathrm{jt}} / \mathbf{P}_{\mathbf{j t}}\right)^{\lambda / \lambda}\right]$ & $\begin{array}{l}50.9 \\
(48)\end{array}$ & $\begin{array}{c}-2.28 \\
(2.09)\end{array}$ & $\begin{array}{c}-0.00105 \\
(0.0136)\end{array}$ & $\begin{array}{c}-0.77 \\
(0.62)\end{array}$ & $\begin{array}{c}-0.0202 \\
(0.0396)\end{array}$ & $\begin{array}{r}-0.000493 \\
(0.00228)\end{array}$ \\
\hline$A_{j t}\left(H_{j t}^{\lambda} / \lambda\right)$ & $\begin{array}{c}47.4 \\
(5.39)^{*}\end{array}$ & $\begin{array}{c}4.32 \\
(0.316)^{*}\end{array}$ & $\begin{array}{c}0.00922 \\
(0.00279)^{*}\end{array}$ & $\begin{array}{c}0.607 \\
(0.143)^{*}\end{array}$ & $\begin{array}{c}0.0301 \\
(0.0141)^{*}\end{array}$ & $\begin{array}{c}0.00726 \\
(0.00155)^{*}\end{array}$ \\
\hline$A_{j t}\left(T_{j t}^{\lambda} / \lambda\right)$ & $\begin{array}{c}0.0678 \\
(0.0587)\end{array}$ & $\begin{array}{l}0.0533 \\
(0.109)\end{array}$ & $\begin{array}{c}0.0112 \\
(0.0322)\end{array}$ & $\begin{array}{c}-0.00447 \\
(0.0252)\end{array}$ & $\begin{array}{l}0.000499 \\
(0.0391)\end{array}$ & $\begin{array}{c}0.0691 \\
(0.0985)\end{array}$ \\
\hline$A_{j t}\left(Y_{j t-1}\right) / \lambda$ & $\begin{array}{l}0.432 \\
(0.0686)^{*}\end{array}$ & $\begin{array}{l}0.116 \\
(0.0614)^{*}\end{array}$ & $\begin{array}{l}0.722 \\
(0.0721)^{*}\end{array}$ & $\begin{array}{l}0.807 \\
(0.0499)^{*}\end{array}$ & $\begin{array}{l}0.789 \\
(0.0627)^{*}\end{array}$ & $\begin{array}{l}0.946 \\
(0.0391)^{*}\end{array}$ \\
\hline$\gamma^{*}$ & 0.57 & 0.88 & 0.28 & 0.19 & 0.21 & 0.05 \\
\hline$\lambda *$ & -0.6 & -0.3 & 0.3 & -0.2 & 0.16 & 0.45 \\
\hline $\begin{array}{l}95 \% \text { confidence } \\
\text { interval for } \lambda\end{array}$ & $-1.0<\lambda<0.1$ & $-0.8<\lambda<0.2$ & $-0.3<\lambda<1.1$ & $-0.8<\lambda<0.4$ & $-0.4<\lambda<0.7$ & $-0.4<\lambda<1.3$ \\
\hline
\end{tabular}

${ }^{1}$ Standard errors are in parenthesis.

* Estimated coefficient significant at $\alpha=0.05$.

pliances, and does not typically include a corresponding change in the utilization rate of an electric appliance due to the lack of functional overlap. On the other hand, since many gas households would have a mixed appliance stock, or all the appliances in the household would not use the same energy source, it is entirely plausible that gas households, upon receiving a high electric bill, for instance, respond by reducing the usage of all appliances, including those driven by natural gas. If responses of this nature dominated the effect of substitution among appliances, the expected signs for electricity and fuel oil prices would be negative. A final factor influencing the signs is the complementary nature of gas and electricity in most gas-heating systems. A usual system consists of a gas furnace and an electrically-driven fan. The results show both positive and negative effects, indicating the three factors considered above are probably canceling each other out.

The coefficient for real income was not significant for any availability region, indicating that the Engel curves were basically horizontal over the range of real income and natural gas consumption available from the sample. This result is not surprising given the uses of natural gas in the household-primarily space and water heating-since functions of this nature do not lend themselves to different levels of usage for the changes in real income observed in the sample.

The estimated coefficients for the remaining variables were as expected. The information proxy was not significant for any availability region, although the estimated coefficient had the expected positive sign in five of the six regions. The estimates of the coefficients for the lagged dependent variable provided estimates of the adjustment coefficient, $\gamma$. The results show that the regions composed of gasproducing states, groups 1 and 2, adjusted to a new equilibrium following changes in prices or other factors at a fairly rapid rate. A fair amount of inertia was exhibited in the other regions, especially region 5 with an estimated adjustment coefficient of 0.05 .

The linear specification was rejected for the four availability regions where the confidence interval for $\lambda$ did not include the value one. ${ }^{12}$ As shown in Table 3, estimation with a linear specification in these four regions would have resulted in significant bias due to misspecification of the functional form. Several differences are worth noting. First, the ownprice term for the linear estimation was not significant for two regions. Second, significant 
Table 3

Results of Linear Estimation $(\lambda=1)$, Groups 1, 2, 3-2, and 4

\begin{tabular}{|c|c|c|c|c|}
\hline Variable & Group 1 & Group 2 & Group 3-2 & Group 4 \\
\hline$A_{i t}$ & $\begin{array}{r}-0.251 \\
(0.306)\end{array}$ & $\begin{array}{c}0.583 \\
(0.268)^{*}\end{array}$ & $\begin{array}{l}0.52 \\
(0.196)^{*}\end{array}$ & $\begin{array}{c}0.524 \\
(0.183)^{*}\end{array}$ \\
\hline $\mathbf{A}_{\mathrm{it}}\left[\left(\mathbf{P}^{\mathbf{i}}{ }_{\mathrm{it}} / \mathbf{P}_{\mathrm{it}}\right)^{\mathrm{A} / \lambda}\right]$ & $\begin{array}{c}-47.1 \\
(83.3)\end{array}$ & $\begin{array}{c}10.8 \\
(58.5)\end{array}$ & $\begin{array}{l}-134 \\
(53.3)^{*}\end{array}$ & $\begin{array}{c}-118.6 \\
(35.74)^{*}\end{array}$ \\
\hline$A_{i t}\left[\left(P^{2}{ }_{i t} / P_{i t}\right)^{\lambda / \lambda}\right]$ & $\begin{array}{c}11.2 \\
(15.3)\end{array}$ & $\begin{array}{c}3.33 \\
(8.36)\end{array}$ & $\begin{array}{c}8.44 \\
(7.87)\end{array}$ & $\begin{array}{l}21.6 \\
(7.06)^{*}\end{array}$ \\
\hline$A_{i t}\left[\left(P^{s}{ }_{i t} / P_{i t}\right) / \lambda\right]$ & $\begin{array}{r}-29.2 \\
(30.9)\end{array}$ & $\begin{array}{l}-54.6 \\
(25.5)^{*}\end{array}$ & $\begin{array}{l}8.24 \\
(26.7)\end{array}$ & $\begin{array}{c}-32.8 \\
(34.2)\end{array}$ \\
\hline$A_{i t}\left[\left(I_{i t} / P_{i t}\right)^{\lambda / \lambda}\right]$ & $\begin{array}{l}2.30 \times 10^{-3} \\
\left(5.72 \times 10^{-6}\right)^{*}\end{array}$ & $\begin{array}{c}-2.86 \times 10^{-5} \\
\left(6.82 \times 10^{-6}\right)^{*}\end{array}$ & $\begin{array}{l}-2.21 \times 10^{-5} \\
\left(8.94 \times 10^{-6}\right)^{*}\end{array}$ & $\begin{array}{l}-3.28 \times 10^{-s} \\
\left(5.66 \times 10^{-g}\right)^{*}\end{array}$ \\
\hline$A_{i t}\left(I I_{i t}^{\lambda} / \lambda\right)$ & $\begin{array}{c}6.18 \times 10^{-5} \\
\left(9.17 \times 10^{-6}\right)\end{array}$ & $\begin{array}{l}9.47 \times 10^{-5} \\
\left(7.18 \times 10^{-6}\right)^{*}\end{array}$ & $\begin{array}{l}2.19 \times 10^{-4} \\
\left(1.70 \times 10^{-6}\right)^{*}\end{array}$ & $\begin{array}{c}4.88 \times 10^{-3} \\
\left(7.78 \times 10^{-9}\right)^{*}\end{array}$ \\
\hline$A_{i t}\left(T_{i t}^{\lambda} / \lambda\right)$ & $\begin{array}{c}0.173 \\
(0.155)\end{array}$ & $\begin{array}{c}0.303 \\
(0.263)\end{array}$ & $\begin{array}{c}-0.0681 \\
(0.112)\end{array}$ & $\begin{array}{l}0.2 \\
(0.105)^{*}\end{array}$ \\
\hline$A_{i t}\left(Y_{i t-1}(\lambda)\right.$ & $\begin{array}{l}0.683 \\
(0.0555)^{*}\end{array}$ & $\begin{array}{l}0.386 \\
(0.0837)^{*}\end{array}$ & $\begin{array}{l}0.818 \\
(0.048)^{*}\end{array}$ & $\begin{array}{c}0.676 \\
(0.067)^{*}\end{array}$ \\
\hline$\gamma^{*}$ & 0.32 & 0.61 & 0.18 & 0.32 \\
\hline
\end{tabular}

*Estimated coefficient significant at $\alpha=0.05$.

income effects were found with a linear specification in all regions, with a positive effect in region 1 and negative effects in regions 2, 3-2, and 4. And third, estimation with a linear functional form resulted in estimates of the adjustment coefficient substantially below the estimates found with the more general functional form in regions 1 and 2 and substantially above the estimate for region 4 . The estimate of the adjustment coefficient for region 3-2 was equivalent in both cases.

The likelihood surface for all regions was relatively flat, exhibited by the wide confidence regions for $\lambda$. This situation precluded rejecting the linear specification for the other two regions.

The estimated elasticities and mean lags are shown in Table 4. The average short-run ownprice elasticity was -0.1 and the long-run elasticity was -0.4 . The average time lag for a household to achieve a new equilibrium following a change in the real price of natural gas or other factors was 6.5 years. The lowest elasticities were in regions 1 and 2, the major natural gas producing areas, and region 5, the area that has been a primary beneficiary of the large interstate natural gas pipeline system. The shortest adjustment times were in regions 1 and 2, and the longest time was in region 5.

Table 4

Own-Price Elasticities and Mean Adjustment Lag By State Group

\begin{tabular}{|c|c|c|c|c|}
\hline & $\begin{array}{l}\text { Own-Price } \\
\text { Short-Run } \\
\text { Elasticity }{ }^{1}\end{array}$ & $\begin{array}{l}\text { Own-Price } \\
\text { Long-Run } \\
\text { Elasticity }\end{array}$ & Mean Lag & $\begin{array}{c}\text { Standard Error } \\
\text { of the } \\
\text { Mean Les }\end{array}$ \\
\hline Group 1 & -0.09 & -0.16 & 0.75 & 1.15 \\
\hline Group 2 & -0.14 & -0.31 & 0.14 & 0.44 \\
\hline Group 3-1 & -0.15 & -0.53 & 2.57 & 3.03 \\
\hline Group 3-2 & -0.16 & -0.86 & 4.26 & 4.74 \\
\hline Group 4 & -0.16 & -0.72 & 3.76 & 4.23 \\
\hline Group 5 & -0.03 & -0.46 & 15.67 & 16.16 \\
\hline Average & -0.1 & -0.4 & 6.5 & \\
\hline
\end{tabular}

'All elasticities were computed at the means.

${ }^{2}$ Computed by weighting each group elasticity with the percent of gas households in the group, and summing the results. 


\section{Conclusions}

The methodology used in the preceding analysis allowed an evaluation to be undertaken on the possible effects of functional form specification bias, and the results showed that linear demand functions can be misleading when applied to residential natural gas market data. Further work in this area should include a more complete evaluation of a log-linear functional form, possibly by using a different heteroscedasticity correction which would not constrain the choice of the transformation.

The empirical results indicated that ownprice and weather were the primary factors in determining changes in the quantity of natural gas consumed for a typical gas household. The estimated elasticities in this study were lower, especially in the long-term, than most estimates available from other research efforts. ${ }^{13}$ This result seems to indicate that gas households do vary the utilization rate of the existing gas appliance stock in response to changes in relative prices, but that these same households generally do not switch from gas to electric apliances. This stands to reason given the prevailing price differentials between electricity and gas over the sample period. ${ }^{14}$ Although the variation in model specifications and data make other comparisons difficult, the results from this study concerning alternative fuel prices and the lack of an income effect are not unusual. ${ }^{15}$

Currently, several natural gas pipelines serving major markets in the midwest have in force take or pay contracts signed in the late 1970 s and early 1980 s for high cost gas. Also, due to relatively mild weather over the two heating seasons prior to $1983 / 1984$, the supply of low cost, old gas remains substantial. As a result, some pipeline companies find themselves in the unenviable position of transporting high cost gas to distribution companies and mainline buyers when low cost gas is available. Under this situation, the price of gas in these markets will rise, dramatically in some cases, even more through the 1984-1986 period than it has in the past. The result on the residential sector will be significant as consumers adjust purchases to reflect both the price effect on the budget and the likely wealth effect on expenditures that would result from the transfer of wealth away from households which have previously invested in a natural gas appliance stock. Many households have made these adjustments during the recent periods of increasing natural gas prices. However, under the current regulatory environment, natural gas price increases in several major markets are likely to continue, and possibly accelerate, over the next few years unless costly take or pay contracts are substantially changed.

Whatever happens on the price deregulation issue, the results of the preceding analysis have shown that price changes will not immediately lead to large changes in the amount of natural gas consumed by households. As the price of gas approaches, and possibly exceeds, that for other energy sources, however, it is likely that the estimates of response patterns presented in this paper may be underestimated since alternatives would become more viable. The most obvious policy course would allow gradual price deregulation on all gas without creating market distortions such as currently exist. Households would have a period of time to adjust the appliance stock mix and would thereby avoid the worst effects of the current and most likely future situation in the United States natural gas markets.

\section{FOOTNOTES}

'For instance, Appelbaum [1] and Chang [10] used this technique with time series data, Bender, Gronberg, and Hwang [6] with cross section data, and Chang and Lee [11] with pooled cross section and time series data.

'For instance, see Blattenberger, Taylor, and Rennhack [7], Barnes, Gillingham, and Hagemann [4], Bloch [8], Beierlein, Dunn, and McConnon [5], Cho [13], Cohn, Hirst, and Jackson [14], Anderson [2], Balestra and Nerlove [3], Chern [12], MacAvoy and Pindyck [20], and Randall, Ives, and Ryan [21].

'Other authors have used the total number of households in the denominator instead of the number of gas households. The use of the latter definition results in a dependent variable that accounts for both the average gas household consumption and the ratio of gas households to total households, and therefore reflects the relative importance of market size for each observation.

Total residential consumption equals the number of gas households times the average consumption per household. Therefore, a dependent variable which is the ratio of total residential gas consumption to total households can be rewritten as the number of gas households divided by the total number of households times the average gas household consumption. Due to the regulatory environment and physical constraints of adding new households to an existing gas system, the use of the total number of households in the denominator may lead to erroneous conclusions concerning market behavior since the factors affecting relative market size will not always be the same as the factors effecting average consumption per gas household. In fact, since natural gas prices were lower to households than fuel oil or electricity during the sample period, the relative market size could be increasing while real incomes were increasing and average household consumption was 
constant, yielding a positive estimate of an income effect that may not be an income effect but a reaction by households to relative prices. Using the average consumption per gas household does not result in this problem.

An exception is offered in Blattenberger, Taylor, and Rennhock [7]. The definition of availability used by these authors is the proportion of the population in a state living in communities served by natural gas pipelines.

The procedure for dealing with past availability was as follows: (1) canonical correlation was used to correlate several past availability measures and current measures of residential natural gas consumption to determine whether a relation did exist, and if it appeared necessary to account for past availability in the analysis; (2) since significant relations were found from the canonical correlations, the results were used to define separate groups of states according to availability characteristics that were identified as being important from the canonical analysis; and (3) the residential natural gas demand model of equation (1) was estimated for each group of states. A complete discussion of this technique is provided by Grady, [16, Chapter 3]. All availability measures were defined for 1968 while consumption measures were 1978 values. A five year difference, 1973 and 1978, was tried and yielded equivalent results. The first three canonical correlation coefficients were significant at the $\alpha=0.05$ level, indicating a strong relation did exist. Significance was determined by comparing the canonical correlation coefficients with critical values of the distribution of the greatest characteristic root [17, p. 300-310]. Consumption measures (by state): (1) gas production per residential gas customer, (2) residential to total quantity of gas consumed, (3) residential gas customers to total households, and (4) residential gas to electric consumption. Availability measures (by state): (1) total miles of gas pipelines to state area, (2) total miles of gas pipelines per household, (3) marketed production per household, and (4) marketed production per metropolitan population.

-Due to core space limitations in the computer utilized for this analysis, group 3 was subdivided into two groups as noted in Table 1. Group 3-1 was defined on the basis of geography and consisted of the southern states along the eastern seaboard and interior southern states. Also, due to data limitations, Hawaii was not included in further analysis.

'Data references are available from the author. The dependent variable was the total residential consumption divided by the total number of residential customers. The natural gas price was the average price, computed by dividing total revenue of gas utility companies from residential sales by total quantity of gas sold. Blattenberger, Taylor, and Rennhack [7] used the utility fixed charge and the marginal price of gas. Their results showed the fixed change was not significant. The electricity price was computed in the same manner. Prices for fuel oil were the average prices paid by farmers in each state. Household income was the ratio of total state personal income to the number of households in the state. Heating degree days were determined as a weighted average, by population, of the heating degree days reported by each weather reporting station in a state. And the gas appliance market share measure was the ratio of residential gas customers to total households.

"The ability of a gas household to respond to changes in the relative price of natural gas is limited by the fact that appliance functions within the household do not typically overlap. Therefore, to respond to large price changes or other factors, the household may have to alter the appliance stock, a process that is not accomplished quickly since most major appliances have fairly long useful lives.

'Kmenta [19, p. 323]. If all terms of the regression are weighted by $\sim \mathrm{N}_{\mathrm{jt}}$, where $\mathrm{N}_{\mathrm{jt}}$ is the number of residential customers in state $j$ at time $t$, the variance would be homoscedastic.

${ }^{10}$ Using the weighting correction and the technique of Wallace and Hussain, both sources of suspected heteroscedasticity, unequal sample size and other, unobservable factors, are taken into account.

"The Statistical Analysis System (SAS) procedures were used for ordinary least squares estimation. The residuals were then used to estimate the elements of $\Omega$ and generalized least squares estimation was performed. A program was written by the author to estimate the elements of $\Omega$ from the OLS residuals, apply GLS estimation, and compute the necessary information to determine $L_{\max }(\lambda)$ from equation (8). This program was written as part of the SAS package under the procedure titled "Matrix." This procedure was repeated for several revelant values of $\lambda$. The determinant of the $\Omega$ matrix was computed as the product of the eigenvalues.

12The confidence interval was estimated using the likelihood-ratio suggested by Box and $\operatorname{Cox}[9$, p. 216].

${ }^{13}$ Using a logarithmic specification, Blattenberger, Taylor, and Rennhack [7] estimated a long run own-price elasticity at -0.39 . Their data set was fairly similar to the one used in this analysis.

${ }^{14}$ For instance, the average relative price of natural gas per 1000 BTUs varied from a low of $1.03 \times 10^{-2}$ cents in Group 2 to a high of $1.74 \times 10^{-2}$ in Group 4, while the comparable figures for electricity were $6.72 \times 10-2$ in Group 3-1 and 7.56 $\times 10^{-3}$ in Group 5. Differences of a similar magnitude prevailed throughout the sample period.

${ }^{16}$ For instance, Beierlein, Dunn, and McConnon [5] and Randall, Ives, and Ryan [21] found no appreciable income effect. Also, Anderson [2] found no income effect when using a dependent variable defined similar to the dependent variable used in this analysis.

\section{REFERENCES}

Appelbaum, Elie. "On the Choice of Functional Forms," International Economic Review, Vol. 20, No. 2 (June, 1979). [1]

Anderson, Kent P. Residential Energy Use: An Econo metric Analysis. A Report Prepared by Rand Corporation for the National Science Foundation, Report No. R-1297-NSF. Santa Monica, Ca.: The Rand Corporation (October, 1973). [2]

Balestra, Pietro, and Marc Nerlove. "Pooling Cross Section and Time Series Data in the Estimation of a Dynamic Model: The Demand for Natural Gas," Econo metrica, Vol. 34, No. 3 (July, 1966). [3]

Barnes, Roberta, Robert Gillingham and Robert Hageman. "The Short-Run Residential Demand for Natural Gas," The Energy Journal, Vol. 3, No. 1 (1982). [4]

Beierlein, James G., James W. Dunn, and James C. McConnon, Jr. "The Demand for Electricity and Natural Gas in the Northeastern United States," The Review of Economics and Statistics, Vol. LXIII, No. 3 (August, 1981). [5]

Bender, Bruce, Timothy J. Gronberg, and Hae-shin Hwang. "The Choice of Functional Form and the Demand for Air Quality," The Review of Economics and Statistics, Vol. LXII, No. 4 (November, 1980). [6]

Blattenberger, Gail R., Lester D. Taylor, and Robert K. Rennhack. "Natural Gas Availability and the Residential Demand for Energy," The Energy Journal, Vol. 4, No. 1 (1983). [7]

Bloch, Farrell E. "Reaidential Demand for Natural Gas," Journal of Urban Economics, 7 (May, 1980). [8]

Box, G. E. P., and D. R. Cox. "An Analysis of Transformations," Joumal of the Royal Statistical Society, Series B, Vol. 26, No. 2 (1964). [9] 
Chang, Hui-shyong. "Functional Forms and the Demand for Meat in the United States," The Review of Economics and Statistics, Vol. LIX, No. 3 (August, 1977). [10]

Chang, Hui-shyong, and Cheng F. Lee. "Using Pooled Time-Series and Cross-Section Data to Test the Firm and Time Effects in Financial Analysis," Journal of Financial and Quantitative Analysis (September, 1977). [11]

Chern, Wen S. Energy Demanded and Interfuel Substitution in the Combined Residential and Commercial Sector. Report No. ORNL/TM-5557. Oak Ridge, Tn.: Oak Ridge National Laboratory (September, 1976). [12]

Cho, Byung, T. "The Residential Demand of Natural Gas: A Principal Components Analysis," 1979 Proceedings of the Business and Economic Statistics Section, American Statistical Association (1979). [13]

Cohn, Steve, Eric Hirst, and Jerry Jackson. Econometric Analyses of Household Fuel Demands. Report No. ORNL/CON-7. Oak Ridge, Tn.: Oak Ridge National Laboratory (March, 1977). [14]

Grady, Stephen T. "Estimation and Evaluation of State Price Indexes for the Period 1967-1978: An Empirical Note," The Review of Regional Studies (Forthcoming). [15]

Grady, Stephen T. Specification and Estimation of Demand Functions: The Residential Demand for Natural Gas. Unpublished $\mathrm{Ph} . \mathrm{D}$. dissertation. The University of Tennessee, Knoxville (June, 1981). [16]

Harris, Richard J. A Primer of Multivariate Statistics. New York, et al.: Academic Press (1975). [17]

Johnson J. Econometric Methods. Second Education.
New York, et al.: McGraw-Hill Book Company (1972). [18]

Kmenta, Jan. Elements of Econometrics. New York: The MacMillan Company (1971). [19]

MacAvoy, Paul W., and Robert S. Pindyck. "Alternative Regulatory Policies for Dealing with the Natural Gas Shortage," Bell Journal of Economics and Management Science, Vol. 4, No. 2 (Autumn, 1973). [20]

Randall, Alan, Berry C. Ives, and James T. Ryan. The Demand for Natural Gas and Electricity in the Southwest. Report No. 284. Portales, New Mexico: New Mexico State University Agricultural Experiment Station (June, 1974). [21]

Schlesselman, J. "Power Families: A Note on the Box and Cox Transformation," Journal of the Royal Statistical Society, Series B, Vol. 33, No. 2 (1971). [22]

Tatsuoka, Maurice M. Multivariate Analysis: Techniques for Educational and Psychological Research. New York, et al.: John Wiley and Sons, Inc. (1971). [23]

Wallace, T. D., and Ashiq Hussain. "The Use of Error Components Models in Combining Cross Section with Time Series Data," Econometrica, Vol. 37, No. 1 (January, 1969). [24]

Zarembka, Paul. "Transformation of Variables in Econometrics," in Frontiers of Econometrics, ed. Paul Zarembka. New York, et al.: Academic Press (1974). [25]

Zellner, A. "An Efficient Method of Estimating Seemingly Unrelated Regressions and Tests for Aggregation Bias," Journal of the American Statistical Association, Vol. 57 (June, 1962). [26] 